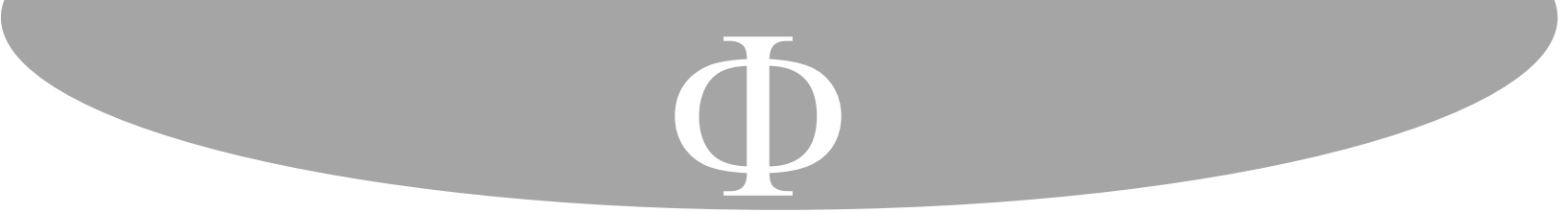

\title{
San Basilio, relato de Dios para la Iglesia*
}

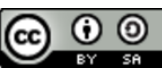

Para citar este artículo: Solano Pinzón, Orlando. «San Basilio, relato de Dios para la Iglesia». Franciscanum
Orlando Solano Pinzón **

Pontificia Universidad Javeriana

Bogotá, Colombia

175, Vol. 63 (2021): 1-22.

\section{Resumen}

El escrito busca argumentar la postulación de san Basilio como un relato de Dios para la Iglesia de todos los tiempos. Se recoge información de las obras del mismo personaje y de aquellos que compartieron con él, además, se apela a comentarios de especialistas que se destacan por el conocimiento del personaje y sus obras. La exposición aborda la experiencia familiar, algunos hechos significativos de su proceso formativo, su incursión en la vida monacal, su ejercicio pastoral como presbítero y obispo de Cesarea, y el carácter contextual de sus escritos.

\section{Palabras clave}

San Basilio, Patrología, Padres de la Iglesia, relato de Dios, iglesia.

\section{Saint Basil, a story of God for the Church}

\begin{abstract}
This document is intended to argue the postulation of St. Basil as a story of God for the Church of all times. It compiles information on the works of the same character and those who shared with him, and also appeals to comments from specialists who stand out for their knowledge of the character and his works. The exhibition deals with the family experience, some significant facts of his formative process, his incursion into monastic life, his pastoral exercise as a priest and bishop of Caesarea, and the contextual character of his writings.
\end{abstract}

\section{Key words}

Saint Basil, Patrology, Fathers of the Church, Story of God, Church.

\footnotetext{
* Artículo fruto de investigación en docencia en el curso de patrología impartido en la Facultad de Teología, de la Pontificia Universidad Javeriana.

** Doctor en Teología, Pontificia Universidad Javeriana, Bogotá. Docente de tiempo completo de la Facultad de Teología de la misma universidad; miembro del grupo de investigación Academia. Contacto: o.solano@javeriana.edu.co. ORCID: https://orcid.org/0000-0003-4446-626X.
} 


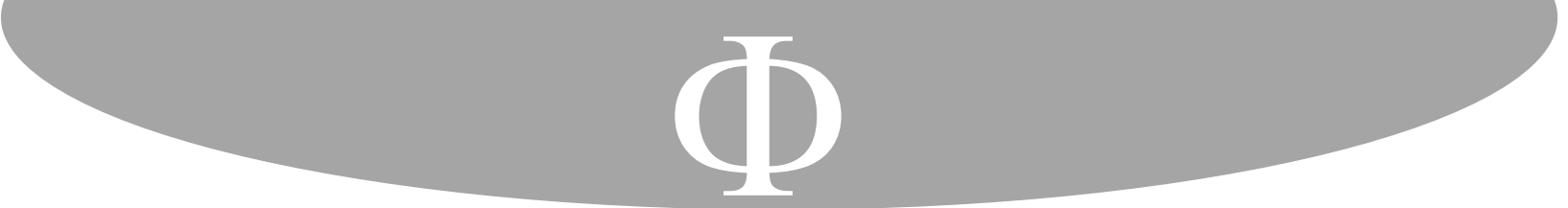

agudizaba el desabastecimiento de alimentos y el foco de hambruna; a lo anterior, se sumaban las comunicaciones precarias, los mensajeros negligentes, la inseguridad general y la preocupación por la información ${ }^{7}$.

Durante su infancia, Basilio recibió de parte de su madre Emelia y de su abuela Macrina, una enseñanza sobre la fe cristiana que va a ser muy significativa y determinante en su vida. El culto a Cristo era tradicional en la familia desde hacía varias generaciones, y muchos de sus miembros habían tenido que sufrir el destierro, el despojo y los malos tratamientos por negarse a ofrecer incienso a los ídolos ${ }^{8}$. Como señala Pérez de Úrbel,

todas estas cosas las oyó por primera vez el pequeño Basilio de labios de su abuela Macrina, con quien pasó sus primeros años en una propiedad que tenía no lejos de las playas del Ponto. Ella misma había sido una de las heroínas de la persecución, que se abatió sobre la Iglesia en los comienzos de siglo?.

En efecto, los primeros gérmenes de la vida cristiana los recibió Basilio de labios de su abuela, mujer intrépida, cuyas virtudes eran de todos conocidas y admiradas en la provincia del Ponto, y a esta primera educación, según Pérez de Úrbel, «debemos atribuir en gran parte el celo, la doctrina, la actividad, la intrepidez heroica y la prudencia del futuro campeón de la fe» ${ }^{10}$.

Su madre y su abuela sentaron las bases de una experiencia que lejos de perderse con el tiempo, se fue consolidando y sirviendo de criterio de discernimiento frente a los diferentes retos que fueron haciéndose presente en su vida. Sobre este particular afirma el propio Basilio:

La enseñanza sobre Dios que había recibido de mi madre bendita y mi abuela Macrina cuando era niño, la he mantenido con mayor convicción. Al llegar a la madurez de la razón, no cambié mis opiniones de una a otra, sino que cumplí los principios que me entregaron mis padres. Así como la semilla cuando crece es primero pequeña y luego se hace más grande, pero siempre conserva su identidad, no se modifica, sino que se perfecciona gradualmente en crecimiento, por lo que creo que la misma doctrina ha crecido en mi caso a través de etapas que avanzan gradualmente. Lo que tengo ahora no ha reemplazado a lo que tenía al principio ${ }^{11}$.

Así como su madre y su abuela lo iniciaron en la fe, su padre Basilio lo hará en las letras, dada la profesión como rétor que desempañaba en Cesarea. La búsqueda de la verdad, propia de la vida filosófica de la época, se gestó en Basilio desde el seno de su familia y

\footnotetext{
${ }^{7}$ Véase, Benoît Gain, L'Église de Cappadoce au IVe siècle d'après la correspondance de Basile de Cèsarèe (330 - 379) (Roma: Pontificium Institutum Orientale, 1985), 1-30.

${ }^{8}$ Philip Rousseau, Basil of Caesarea, 6.

9 Justo Pérez de Úrbel, San Basilio el grande (Madrid: Héroes de Caridad (Acción Católica), 1942), 17.

${ }^{10}$ Justo Pérez de Úrbel, San Basilio el grande, 18.

${ }^{11}$ Saint Basil, The Letters, Vol. 2 (Washington: The Catholic University of America Press, 1955), 130. Todas las traducciones del presente artículo son nuestras.
} 


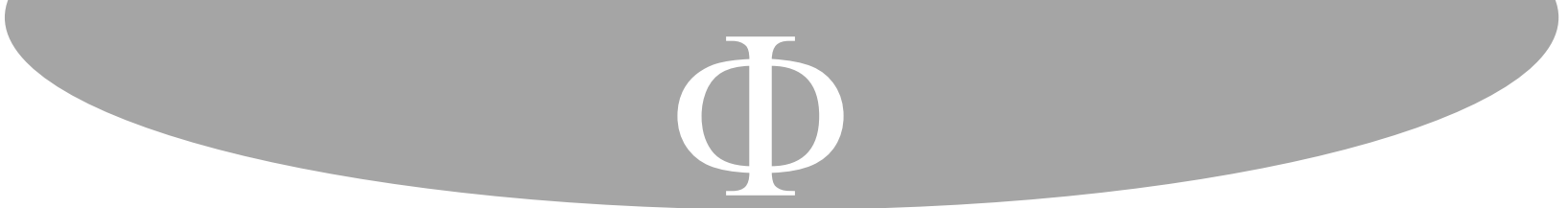

continuó posteriormente en una estancia con el famoso rétor Libanio y en los centros de educación más importantes de la época, Constantinopla y Atenas. De la primera saldrá a relucir la capacidad presente en Basilio para la retórica, que será reconocida y alabada por su maestro Libanio. Es oportuno recordar que la educación antigua era fuertemente retórica en la intención y en el contenido. Y, como señala Meredith, «su objetivo principal, aunque de ninguna manera exclusivo, era producir oradores efectivos» ${ }^{12}$.

En el epistolario de Basilio, particularmente las cartas 341 y 345 que dirige Libanio a Basilio, en la primera, el maestro le da el calificativo de boca de oro ${ }^{13}$; y en la segunda, el maestro se expresa en los siguientes términos: «Soy el mismo hombre que siempre corría cuando aparecías, y que escuchaba con gran alegría la corriente de tu elocuencia; regocijándome de escucharte; con dificultad para arrancarme» ${ }^{14}$.

Durante la estadía en Atenas, Basilio entablará amistad con Gregorio de Nacianzo, con quien consolidará una gran amistad. Este gusto por la amistad, por buscar ser un gran amigo, será una constante en Basilio, aunque ello le acarreará algunas desilusiones ${ }^{15}$. Particularmente, Gregorio en el discurso 43 dedicado a Basilio da cuenta de esa experiencia de amistad vivida con Basilio en los siguientes términos:

Nos habíamos encontrado en Atenas, como el curso de un río que, naciendo en una misma patria, se divide luego hacia diversas regiones (a donde habíamos ido por el afán de aprender) y de nuevo, de común acuerdo, por disposición divina, vuelve a reunirse (...) Por entonces, no sólo admiraba yo a mi grande y querido Basilio, por la seriedad de sus costumbres y por la madurez y prudencia de sus palabras, sino que inducía también yo mismo a los demás que no lo conocían a que le tuviesen esta misma admiración. Los que conocían su fama y lo habían oído ya lo admiraban. ¿Qué consecuencias tuvo esto? Que él era casi el único que destacaba entre todos los que habían venido a Atenas para estudiar, y que alcanzó honores superiores a los que correspondían a su condición de mero discípulo. Éste fue el principio de nuestra amistad, el pequeño fuego que empezó a unirnos; de este modo, se estableció un mutuo afecto entre nosotros ${ }^{16}$.

No sólo las dotes de elocuencia y oratoria de Basilio despertaban interés en sus contemporáneos y compañeros de estudios más cercanos. Basilio mostró igualmente una sensibilidad especial en su periodo formativo, en términos de sus relaciones fraternales. Siguiendo este discurso 43 de Gregorio de Nacianzo, resulta evidente que la amistad entre ellos partía de una mutua admiración y estima, del compartir espacios de vida y camaradería,

\footnotetext{
${ }^{12}$ Anthony Meredith, The Cappadocians (New York: Vladimir's Seminary Press Crestwood, 2000), 7.

${ }^{13}$ Saint Basil, The Letters, Vol. 2, 325.

14 Saint Basil, The Letters, Vol. 2, 327.

${ }^{15}$ Un caso particular es el referido a la amistad que había entablado con Eustasio de Sebaste, a quien admiró por su esfuerzo en la búsqueda de la virtud, pero de quien se distanció debido a su negativa de aceptar la divinidad del Espíritu Santo. Basilio no podía concebir que un hombre que en la virtud era inquebrantable, pudiera variar en la doctrina. Véase, Claudio Moreschini, Introduzione a Basilio il Grande, 26. Philip Rousseau, Basil of Caesarea, 174.

${ }^{16}$ Grégoire de Nazianze, Discours 42-43 (Paris: Du Cerf, 1992), 43, 16-17.
} 


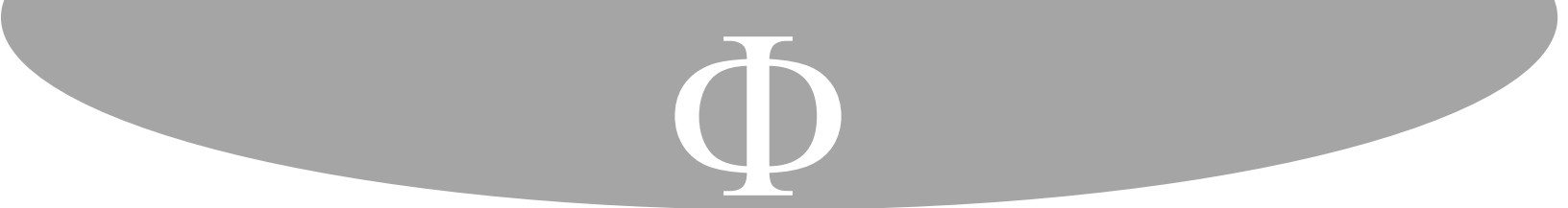

su convicción, según Spidlik, era que: «Las Escrituras son la voz de Dios a las cuales el cristiano debe someterse sin reserva» ${ }^{31}$.

Más aún, su más íntima inclinación en su meditación de las Escrituras era, según Moreschini «unir los aspectos morales con los aspectos sociales y prácticos del cristianismo. $\mathrm{Su}$ actividad y su retórica pretendían despertar en su audiencia el deseo de crecimiento espiritual y moral» ${ }^{32}$. A la base de la intencionalidad antes descrita, el modelo que Basilio busca imitar se asemeja al asumido antes por Pacomio, esto es, según Moreschini,

a la iglesia más antigua de Jerusalén, la que se presenta en los Hechos de los Apóstoles, es decir, la de perfecta hermandad cristiana. El término adelphotes, «hermandad», aparece muy a menudo en sus escritos, marcado por una fuerte huella social. La comunidad, según Basilio, no es un medio que permita a cada uno de sus miembros llevar una vida personal, sino que es el fin al que tiende la acción de todos ${ }^{33}$.

En el proceso de gestación de la experiencia monacal cenobítica adelantada por Basilio, se unió su amigo Gregorio de Nacianzo, con quien compartió el ideal de vida caracterizado por las practicas diarias de la salmodia comunitaria, el trabajo manual acompañado de oración secreta, el canto de himnos, la lectura y meditación de la Escritura y la oración personal ${ }^{34}$.

Además, con este amigo adelantó un trabajo importante de recuperación del legado de Orígenes de Alejandría, que dio lugar a una obra publicada alrededor del 358 con el título de Filocalia ${ }^{35}$. Según Pérez de Úrbel, con temperamentos diferentes, el uno más austero y el otro más apacible; el uno más orientado hacia las enseñanzas de la ciencia, y el otro más atraído por los encantos de la poesía, «ambos eran igualmente fervorosos en la oración, igualmente puros en sus costumbres, igualmente entusiastas de las letras, de los poetas clásicos, de la elocuencia» ${ }^{36}$.

\section{Un pastor consagrado a Dios y al servicio de los más necesitados}

La dedicación exclusiva a llevar adelante esta experiencia monástica no va a durar mucho tiempo, pues con un perfil como el que hasta el momento se ha descrito, no podía pasar desapercibido. Por esta razón, muy pronto fue convocado por Dianius, obispo de Cesarea, como su consejero para abordar el tema candente del arrianismo. La posibilidad de seguir con dedicación exclusiva en el monasterio será cada vez menor, pues muy pronto será ordenado diácono (360) y posteriormente presbítero (362). Al quedar libre la sede de Cesarea

\footnotetext{
${ }^{31}$ Thomas Spidlik, «L'idéal du monachisme basilien», en Basil of Caesarea: christian, humanist, ascetic. A Sixteen-Hundredth Anniversary Symposium (361-374), ed. Paul Jonathan Fedwick (Toronto: Pontifical Institute of Mediaeval Studies, 1979), 363.

${ }^{32}$ Claudio Moreschini, Introduzione a Basilio il Grande, 61.

${ }^{33}$ Claudio Moreschini, Introduzione a Basilio il Grande, 74.

${ }^{34}$ Véase, Garcia M. Colombás, El monacato primitivo (Madrid: BAC, 2004), 187.

35 Véase, Anthony Meredith, The Cappadocians, 10.

36 Justo Pérez de Úrbel, San Basilio el grande, 24.
} 


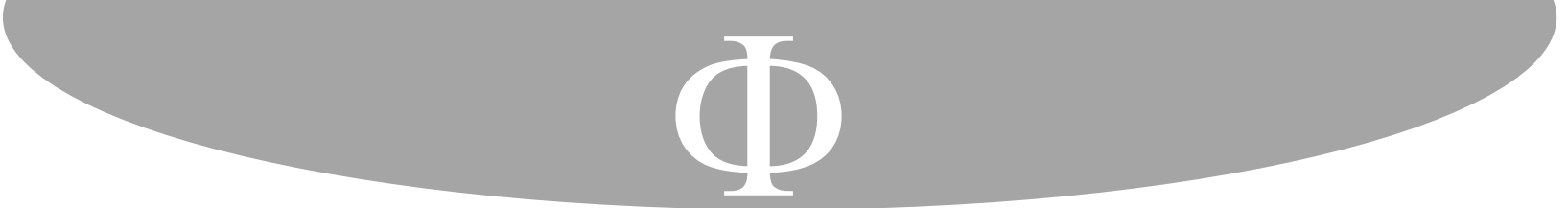

por la muerte del titular, será ordenado obispo (370), labor a la que dedicará la totalidad de su tiempo.

Es oportuno señalar, que el papel que cumplió Basilio en esta nueva etapa de su vida, se comprende mejor al entender la función preponderante que adquirió la figura del obispo al interior de la Iglesia y de la sociedad ${ }^{37}$. Ramón Teja, un especialista en la historia y la literatura antigua, señala que el mundo greco-romano dio lugar a una variedad de figuras que dinamizaron la civilización antigua, entre ellas, al político, al sacerdote, al jurista, al filósofo, al rétor, etc. Entre estas figuras no es posible parangonar al obispo, aunque en el plano social asuma un poco de cada una de ellas ${ }^{38}$.

Ahora bien, la influencia del obispo en la sociedad del Imperio romano tardío es evidente y entre otros factores es consecuencia tanto de la política religiosa de los emperadores cristianos, como del acceso al episcopado de una larga serie de personajes que, por su status social, su riqueza familiar, su formación cultural estaban llamados de por sí a dirigir la sociedad de su tiempo. Lo anterior explica, según Teja,

el que la mayoría de los obispos orientales procediesen de las aristocracias urbanas representadas por los rangos curiales y que su acceso a la carrera eclesiástica se presentase para ellos como la posibilidad de conservar y reforzar el papel político y la influencia social que en la vida civil encontraba la competencia siempre creciente de las estructuras estatales a través del poder reforzado de los funcionarios ${ }^{39}$.

En correspondencia con lo anterior es posible afirmar que el poder episcopal se colocó, tanto a nivel ideológico como a nivel operativo, al mismo nivel del poder político ${ }^{40}$. Este prototipo de obispo que se consolidó en la Capadocia del siglo IV permite comprender mejor las razones que llevaron a Basilio, una vez elegido Obispo de la sede metropolitana de Cesarea en el 370 y dado el conflicto que había con los obispos afectos al arrianismo ${ }^{41}$, a

\footnotetext{
${ }^{37}$ Según Claudio Moreschini, «Nella sua struttura istituzionale Ia gerarchia ecclesiastica, a partire dal IV secolo, rispecchio quella della amministrazione municipale ed imperiale. Ogni città aveva un vescovo e le "province" della Chiesa generalmente corrispondevano alle province dell'Impero; le città piu importanti erano di solito anche le sedi metropolitane e i vescovi spesso si incontravano in concili provinciali. Anche le consuetudini dei Padri Cappadoci nella amministrazione della loro Chiesa (ad esempio per la successione episcopale) non furono diverse da quelle della prassi della societa pagana. Nel procurarsi gli uffici statali, lo instrumento più idoneo era il patronato fornito dai parenti, dagli amici e dai legami con altri magistrati, talvolta con lo stesso imperatore: queste esigenze potevano influire anche sull' elezione del vescovo. Nella scelta dei sacerdoti i Cappadoci più di una volta proclamano di non lasciarsi influenzare da motivi esterni: l'esempio da seguire era, secondo loro, quello di Gregorio il Taumaturgo». Claudio Moreschini, I Padri Cappadoci, storia, letteratura, teología (Roma: Cittá Nuova, 2008), 16.

38 Véase, Ramón Teja, Emperadores, obispos, monjes y mujeres, protagonistas del cristianismo antiguo (Madrid: Trotta, 1999), 75.

${ }^{39}$ Ramón Teja, Emperadores, obispos, monjes y mujeres, protagonistas del cristianismo antiguo, 75-76.

${ }^{40}$ Véase, Ramón Teja, Emperadores, obispos, monjes y mujeres, protagonistas del cristianismo antiguo, 78.

${ }^{41}$ Según José Fernández Urbina, «el arrianismo tuvo en vilo a la Iglesia y al imperio durante casi todo el siglo IV, particularmente en las provincias orientales por motivos de hondo calado teológico que les llevaba a rechazar el trinitarismo niceno al identificarse con los postulados subordinacionistas que consideraban al Hijo inferior en mayor o menor grado al Dios Padre. Dicho movimiento tendría luego una larga pervivencia en los
} 


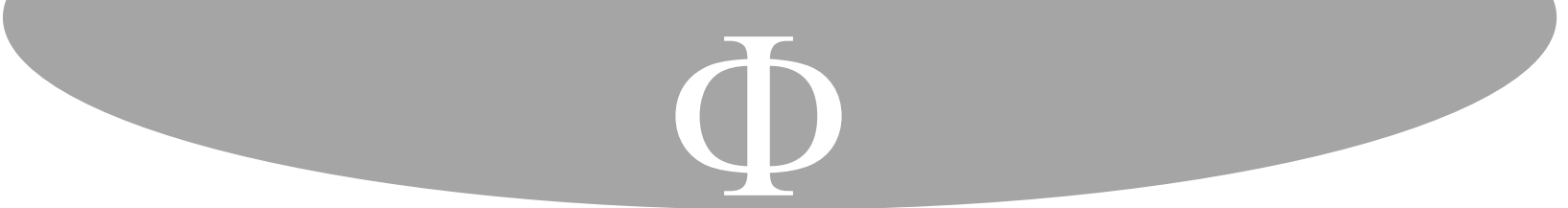

ordenar como obispos a su hermano Gregorio, a su amigo Gregorio de Nacianzo y a Anfiloquio de Iconio. Estos personajes, debido a su vasta formación y elocuencia ${ }^{42}$ podían ayudarle, tanto en su defensa de la fe proclamada en Nicea que había heredado de San Atanasio, como con la política eclesiástica que había iniciado tras su elección, para afianzar la unidad de la Iglesia ${ }^{43}$.

Si bien Basilio proviene de un medio social aristócrata, es su experiencia de fe la que determina la particularidad de su modo de asumir el ejercicio del episcopado y de comprender las funciones emanadas de este ejercicio, lo que significa un modo particular de comprender y apropiarse de este ministerio, al punto que Gribomont al referirse al obispo de Cesarea usa la expresión: «aristócrata revolucionario» ${ }^{44}$. Son muchos los ejemplos a los que se pudiera hacer alusión para dar cuenta del talante de Basilio en su ejercicio como obispo, pero por razones de espacio es oportuno mencionar tres.

El primero tiene que ver con su celo apostólico en función de salvaguardar la verdad de la fe recibida de la Tradición que remite directamente a los Apóstoles. El concilio de Nicea había definido que el Hijo es consubstancial con el Padre, corrigiendo la pretensión arriana que concebía al Hijo como una criatura. Pero dicho concilio no explicó debidamente el alcance de lo definido, por lo cual, los años posteriores a Nicea estuvieron dedicados a profundizar y explicar el sentido de la expresión definida por dicho Concilio. La labor de Basilio será vital en este ejercicio de aclaración, que no será fácil, pues el arrianismo sabía sacar provecho de la influencia de los emperadores que eran afectos a sus ideas, para extender su dominio sobre las sedes episcopales. Frente a esta coyuntura, Basilio afirma:

Nuestras angustias son notorias, aunque las dejamos sin contar, porque ahora su sonido se ha extendido a todo el mundo. Las doctrinas de los Padres son despreciadas; las tradiciones apostólicas se ponen en nada; las ideas de los innovadores están de moda en las Iglesias; ahora los hombres son más bien inventores de sistemas astutos que teólogos; la sabiduría de este mundo gana los premios más altos y ha rechazado la gloria de la cruz $^{45}$.

reinos germánicos». José Fernández Urbina, «Constantino y el triunfo del cristianismo en el Imperio Romano, (329-397)», en Historia del Cristianismo. El mundo Antiguo, eds. Manuel Sotomayor y José Fernández Urbina (Madrid: Trotta, 2003), 350-352.

${ }^{42}$ Según Blázquez, «la elocuencia era entonces la enseñanza más necesaria para triunfar en la vida eclesiástica y en la civil (...) todas las ciudades de origen antiguo, no reciente, tienen algo de que enorgullecerse, por leyendas o por lo que se puede ver en ellas. Cesarea se distingue por la elocuencia, como seña de identidad cultural, que se opone a la fuerza de las armas o a la violencia de los espectáculos teatrales». José María Blázquez, «La Academia de Atenas como foco de formación humanística para paganos y cristianos: Los casos de Juliano, Basilio y Gregorio Nacianceno», Gerión 19 (2001): 609. Para Quasten, los padres capadocios «reúnen en sus personas, juntamente con una excelente preparación teológica, una gran cultura helenística, brillante elocuencia y dominio del estilo, todo ello aprendido en escuelas y academias antiguas». Johannes Quasten, Patrología II (Madrid: BAC, 1973), 3.

${ }^{43}$ Véase, Ramón Teja, Emperadores, obispos, monjes y mujeres, protagonistas del cristianismo antiguo, 87. Johannes Quasten, Patrología II, 227, 262, 282.

44 Jean Gribomont, «Un aristocrate révolutionnaire, évêque et moine», Augustinianum 17 (1977): 179-191.

${ }^{45}$ Saint Basil, The Letters, Vol. 1, 199, 200. 


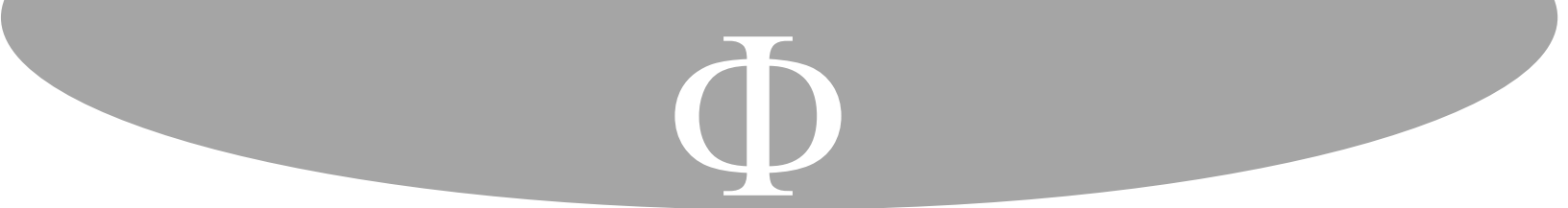

el testimonio de solidaridad y hospitalidad de sus padres y sus abuelos frente a las personas necesitadas $^{49}$.

Por esta razón, no en vano desde el inicio de su experiencia monástica y posteriormente desde su función como obispo, se esforzó por promover la sensibilidad social, tanto entre los superiores de los monasterios, como entre los obispos. Esta preocupación por lo social se hizo concreta de muchas maneras: desde el desprendimiento de los propios bienes, la defensa de personas vulnerables, la organización de grandes obras de caridad como hospitales, escuelas, hostales, distribución de alimentos a los pobres, que despertaron la envidia de las autoridades imperiales. Según Allard, el gobernador estaba asustado, veía en el obispo un rival ${ }^{50}$; las construcciones dedicadas a la caridad se encontraban a las afueras de la ciudad, dando la sensación de una ciudad paralela, a la que Gregorio de Nacianzo dio el apelativo de «ciudad nueva» y a la cual el pueblo designó con la palabra Basiliada, nombre con el que fue nominada hasta el siglo $\mathrm{V}^{51}$.

En cuanto a la actitud de desprendimiento frente a las cosas materiales, se destaca la distribución que hizo de la herencia recibida tras la muerte de su padre, ya antes aludida. Posteriormente, en una de las épocas de sequía a la que siguió otra de hambre, Basilio hizo uso de todos los bienes que le había heredado su madre Emelia, los vendió y distribuyó el producto entre los más necesitados. Esta sensibilidad social se entiende en Basilio desde su comprensión según la cual el mundo en su multiplicidad, ritmo y orden no tiene otro objetivo, según Spidlik, «que ser un "recuerdo" de nuestro contacto con Dios. Si la mente humana fue creada para recordar a Dios, las cosas materiales, a su vez, tienen la intención de evocar esa memoria. Esa es su verdadera naturaleza» 52 .

Desde esta comprensión se pueden entender mejor las expresiones de Basilio que aborda en la homilía sobre el dicho del Evangelio de Lucas: «derribaré mis depósitos y construiré otros más grandes» (Lc 12,8), en relación con el tema de la pobreza:

El pan que tienes en exceso no te pertenece sino al hambriento; la ropa que guardas en tus armarios pertenece solo a los desnudos; los zapatos que se pudren en tus armarios

\footnotetext{
49 Véase, Grégoire de Nazianze, Discours funèbres en l'honneur de son frère césaire et de basile de césarée, 75.

50 Véase, Paul Allard, Saint Basil (París: Librairie Victor Lecoffre, 1903), 111.

${ }^{51}$ Según el Nuovo Dizionario Patristico, la Basiliada tenía como objetivo «accogliere e curare i lebbrosi, i feriti, i maláti, i poveri, i pellegrini. La città, che prese il nome da Basilio, si presenta come attuazione dei principi evangelicí di poverta e di apertura caritatevole a chi e nel bisogno, poverta e apertura che nascono come esigenza intrínseca dall' essere seguací e imitatori di Gesii. Cristo. La città di Basilio esercíto un'ampia attrattiva sulla gente tanto che gradualmente la città antica fu abbandonata e la città-ospizio di s. Basilio mantenne il nome di «città nuova» ancora dopo un secolo». Maria Grazia Bianco, «Basiliade», en Nuovo Dizionario Patrístico e di Antichità Cristiane, Vol. I, Di Berardino, Angelo, Dir. (Genova: Marietti Editrice, 2006), 720-721.

52 Thomas Spidlik, «L'idéal du monachisme basilien», 372 -373.
} 


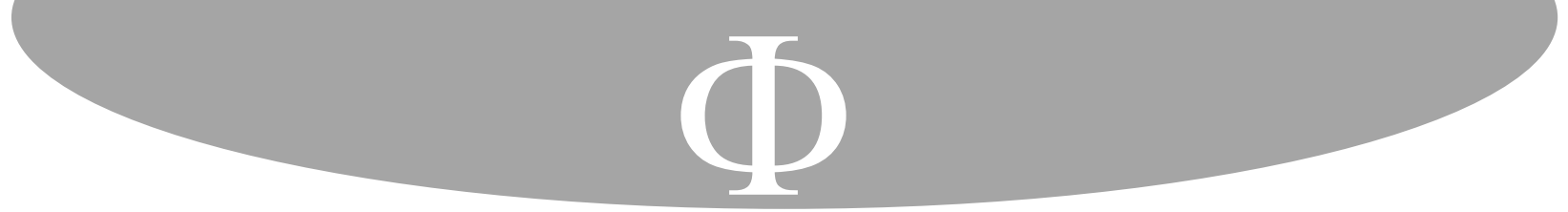

oficios altamente especializados, bien orientados al servicio doméstico, bien a la administración de la hacienda y la casa de sus señores como notarios, contables, etc. La vida de la mayor parte de estos esclavos se desarrollaba en estrecho contacto con el dueño, se generaban estrechas afectividades entre ellos y era frecuente incluso que participasen en la herencia de sus señores ${ }^{59}$.

Esta forma de esclavitud hacía que estos esclavos tuvieran unas condiciones de vida más favorables, en comparación con una buena masa de la población a quienes Basilio califica como pobres y hacia quienes se orientaron principalmente sus preocupaciones sociales. Más aún, en palabras de Teja:

En una época como esta, en que los lazos de dependencia personal jugaban un papel social de primera importancia, era preferible el patrocinio de un poderoso, a una pobreza con la aureola de libertad. Esta protección la tenían asegurada los esclavos pues sus condiciones de vida dependían fundamentalmente del poder económico y social de sus dueños. Por el contrario, los pobres tenían que buscarla en la caridad de los ricos o de la Iglesia. Estas circunstancias explican suficientemente la escasa preocupación social por los esclavos, no solo por parte de Basilio, sino por toda la Iglesia en general al final del mundo antiguo y después en la época medieval ${ }^{60}$.

\section{Carácter contextual de sus escritos}

Basilio es admirable en todos sus escritos por el estilo original, adecuado y, en general, político y panegírico. Como buen rétor, enfatiza el método lingüístico de la persuasión, y al hacer uso magistral de su capacidad retórica, sus palabras fluyen con gran naturalidad, brillantez y dulzura. Como señala Racine, «En la mayoría de sus obras, cita abundantemente la Biblia, como se nota cuando se mira el índice de las Escrituras de cada una de las obras de Basilio» ${ }^{61}$. Además, establece una regla según la cual los términos teológicos deben ajustarse a las Escrituras y se debe evitar la creación de nuevos términos. Según Racine,

Uno puede distinguir dos formas de usar la Biblia en la disputa contra Eunomio y en la obra dedicada al Espíritu Santo. O bien Basilio cita las Escrituras simplemente para ilustrar su discurso o él la usa para verificar la validez de su propio discurso ${ }^{62}$.

En el caso de Basilio como de la mayor parte de los Padres de la Iglesia, la actividad literaria estaba dedicada a responder a problemas concretos que agitaban la vida de las comunidades. A continuación, evocaremos algunos ejemplos que permiten validar la afirmación anterior.

\footnotetext{
${ }^{59}$ Ramón Teja, «San Basilio y la esclavitud: teoría y praxis», 401-402.

${ }^{60}$ Ramón Teja, «San Basilio y la esclavitud: teoría y praxis», 402.

${ }^{61}$ Jean-François Racine, The text of Matthew in the writings of Basil of Caesarea (Atlanta: Society of Biblical Literature, 2004), 19.

62 Jean-François Racine, The text of Matthew in the writings of Basil of Caesarea, 21.
} 
literatura clásica en el plano moral y sabía aprovechar los escritos de los autores paganos a los cuales confería sólo un valor propedéutico a la fe cristiana ${ }^{69}$.

Como buen maestro, Basilio elabora un escrito a manera de mensaje a los jóvenes en el cual les aconseja cómo leer a los clásicos, a continuación, referimos algunos apartes:

Mirad, se cuenta que el gran Moisés, cuya fama de sabio entre todos los hombres es enorme, ejercitó también su inteligencia con las enseñanzas de los egipcios y así avanzó hasta la contemplación del Ser. Y de forma similar a este, pero en época posterior, el sabio Daniel dicen que, después de aprender en Babilonia la sabiduría de los caldeos, se aplicó luego a las enseñanzas divinas (...) Pero aceptaremos, eso sí, aquellas obras suyas en las que ensalzaron la virtud o condenaron el vicio ${ }^{70}$.

Del texto antes señalado queda evidente la referencia directa a la virtud como fundamento y criterio de discernimiento, tanto para entrar en diálogo con la cultura pagana, como para el ejercicio de interpretación alegórica.

Un ejemplo adicional tiene que ver con el epistolario, que según Moreschini constituye un documento de primer orden para conocer a Basilio y su círculo de amigos y enemigos, y porque permite tener una idea de la situación social, política y religiosa de Capadocia $^{71}$. Según Gain, son 330 cartas que gozan de reconocimiento como propias y 35 cartas inauténticas o apócrifas ${ }^{72}$. Los ejemplos del epistolario ya han sido plasmados a lo largo del presente escrito.

\section{Conclusión}

Después de la exposición desarrollada y ante el testimonio de una vida entregada, es oportuno señalar que el final de la vida de Basilio estuvo marcado por una noticia reconfortante. Con la muerte del emperador Valente a finales del 378, el dominio ejercido por los arrianos durante cuarenta y siete años había llegado a su fin. Pero como señala Allard,

Cuando estas felices noticias vinieron a él, el obispo de Cesarea ya estaba en su lecho de muerte. Aunque solo tenía cuarenta y nueve años, el trabajo, la educación, la enfermedad, las dificultades, lo habían convertido en un anciano. Se sentía cerca de su fin $^{73}$.

\footnotetext{
${ }^{69}$ Véase, Gonzalo Balderas Vega, Jesús, cristianismo y cultura en la Antigüedad y en la Edad Media (México: Universidad Iberoamericana, 2007), 186.

${ }^{70}$ Basilio de Cesarea, A los jóvenes: cómo sacar provecho de la literatura griega (Madrid: Ciudad Nueva, 2011), III, 3,4; IV, 7.

${ }^{71}$ Véase, Claudio Moreschini, Introduzione a Basilio il Grande, 9.

${ }^{72}$ Véase, Benoît Gain, L'Église de Cappadoce au IVe siècle d'après la correspondance de Basile de Cèsarèe (330-379), 32.

${ }^{73}$ Paul Allard, Saint Basil, 149.
} 


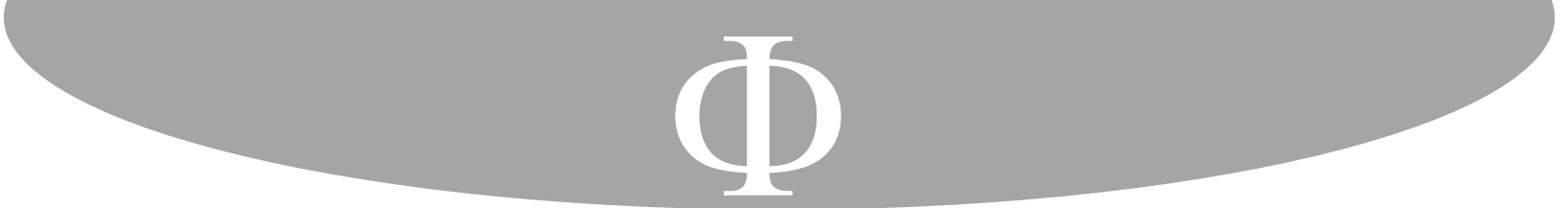

Basilio de Cesarea. A los jóvenes: cómo sacar provecho de la literatura griega. Madrid: Ciudad Nueva, 2011.

Basilio de Cesarea. El Espíritu Santo. Madrid: Ciudad Nueva, 1996.

Basilio de Cesarea. Reglas morales. Madrid: Ciudad Nueva, 2015.

Basilio di Cesarea. «Omelia sull martir Gordio». En Omelie sull'Esamerone e di argomento vario. Editado por Francesco Trisoglio. Milano: Bompiani, 2017.

Basilio di Cesarea. «Omelia sul detto del Vangelo di Luca: "Abbatterò i miei magazzini e ne edificherò dei più grandi” (Lc. 12,8)». En Basilio di Cesarea, Omelie sull'Esamerone e di argomento vario. Editado por Francesco Trisoglio. Milano: Bompiani, 2017.

Bianco, Maria Grazia. «Basiliade». En Nuovo Dizionario Patrístico e di Antichità Cristiane. Vol. I. Dirigido por Angelo Di Berardino. Genova: Marietti Editrice, 2006.

Blázquez, José María. «La Academia de Atenas como foco de formación humanística para paganos y cristianos: Los casos de Juliano, Basilio y Gregorio Nacianceno», Gerión 19 (2001): 595-628.

Colombás, Garcia M. El monacato primitivo. Madrid: BAC, 2004.

Fedwick, Paul Jonathan, Ed. Basil of Caesarea: christian, humanist, ascetic. A SixteenHundredth Anniversary Symposium. Toronto: Pontifical Institute of Mediaeval Studies, 1979.

Fernández Urbina, José. «Constantino y el triunfo del cristianismo en el Imperio Romano, (329-397)». En Historia del Cristianismo. El mundo Antiguo. Editado por Manuel Sotomayor y José Fernández Urbina. Madrid: Trotta, 2003.

Gain, Benoît. L'Église de Cappadoce au IVe siècle d'après la correspondance de Basile de Cèsarèe (330 - 379). Roma: Pontificium Institutum Orientale, 1985.

Grégoire de Nazianze. Discours 42-43. Paris: Du Cerf, 1992.

Grégoire de Nazianze. Discours funèbres en l'honneur de son frère césaire et de basile de $\begin{array}{lllll}\text { césarée. } & \text { Consultada } & 2019 .\end{array}$ https://archive.org/details/discoursfunbre00greg/page/74/mode/2up.

Gregorio de Nisa. Vida de Macrina. Elogio de Basilio. Madrid: Ciudad Nueva, 1995.

Gribomont, Jean. «Un aristocrate révolutionnaire, évêque et moine». Augustinianum 17 (1977): 179-191.

Karayannopoulos, Ioannes. «Saint Basil's social activity: Principles and praxis». En Basil of Caesarea: christian, humanist, ascetic. A Sixteen-Hundredth Anniversary Symposium (361-374). Editado por Fedwick, Paul Jonathan. Toronto: Pontifical Institute of Mediaeval Studies, 1979.

Meredith, Anthony. The Cappadocians. New York: Vladimir's Seminary Press Crestwood, 2000.

Moreschini, Claudio. I Padri Cappadoci, storia, letteratura, teología. Roma: Cittá Nuova, 2008.

Moreschini, Claudio. Introduzione a Basilio il Grande. Brescia: Morcelliana, 2005.

Pérez de Úrbel, Justo. San Basilio el grande. Madrid: Heroes de Caridad (Acción Católica), 1942.

Quasten, Johannes. Patrología II. Madrid: BAC, 1973.

Racine, Jean-François. The text of Matthew in the writings of Basil of Caesarea. Atlanta: Society of Biblical Literature, 2004. 


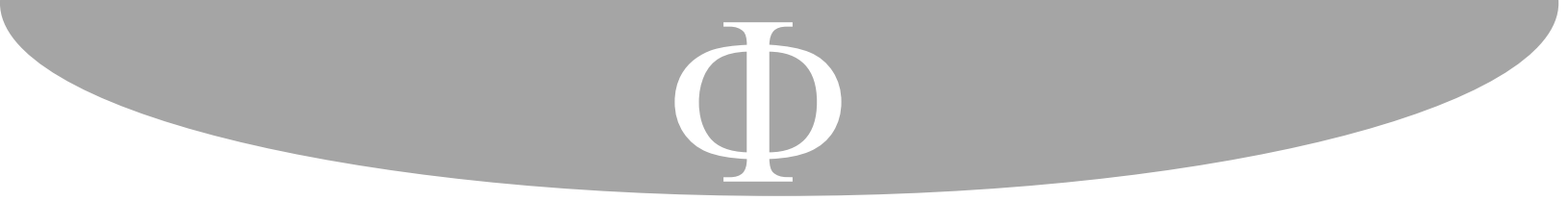

Ramos Jurado, Enrique Ángel. «Paideia griega y fe cristiana en Sinesio de Cirene», Habis 23 (1992): 247-261.

Rousseau, Philip. Basil of Caesarea. Berkeley: University of California Press, 1998.

Saint Basil. The Letters Vol. 1. Washington: The Catholic University of America Press, 1951.

Saint Basil. The Letters Vol. 2. Washington: The Catholic University of America Press, 1955.

Scazzoso, Piero. «San Basilio e la Sacra Scrittura». Aevum 47(1973): 210-224.

Schillebeeckx, Edward. Los hombres relato de Dios. Salamanca: Sígueme, 1994.

Simonetti, Manlio. La crisi ariana nel IV secolo. Roma: Institutum Patristicum, 1975.

Sozomen, Hermias. Historia eclesiástica. Consultada en septiembre 29, 2019. http://ecmarsh.com/fathers/npnf2/NPNF2-02/Npnf2-02-24.htm\#P3974_1746195.

Spidlik, Thomas. «L'idéal du monachisme basilien». En Basil of Caesarea: christian, humanist, ascetic. A Sixteen-Hundredth Anniversary Symposium (361-374). Editado por Fedwick, Paul Jonathan. Toronto: Pontifical Institute of Mediaeval Studies, 1979.

Teja, Ramón. «San Basilio y la esclavitud: teoría y praxis». En Basil of Caesarea: christian, humanist, ascetic. A Sixteen-Hundredth Anniversary Symposium (361-374). Editado por Fedwick, Paul Jonathan. Toronto: Pontifical Institute of Mediaeval Studies, 1979.

Teja, Ramón. Emperadores, obispos, monjes y mujeres, protagonistas del cristianismo antiguo. Madrid: Trotta, 1999.

Trevijano Etchevarria, Ramón. Patrología. Madrid: BAC, 1994.

Enviado: 14 de junio de 2020

Aceptado: 28 de junio de 2020 